\title{
Research and Publication in Brazil: Where we are and Where we Head to
}

\author{
Marcelo Antônio Cartaxo Queiroga Lopes, ${ }^{1}$ (ㄹ) David Brasil, ${ }^{2,3}$ Gláucia Maria Moraes de Oliveira ${ }^{4}$ \\ Hospital João Pessoa, João Pessoa,' PB - Brazil \\ Faculdade de Ciências Médicas de Minas Gerais, ${ }^{2}$ Belo Horizonte, MG - Brazil \\ Universidade Federal de Lavras, ${ }^{3}$ Lavras, MG - Brazil \\ Universidade Federal do Rio de Janeiro, Rio de Janeiro, ${ }^{4} \mathrm{RJ}$ - Brazil
}

In a report by Clarivate Analytics for the Brazilian Coordination for the Improvement of Higher-LevelEducation Personnel (CAPES) about the Brazilian research productivity between 2013 and 2018, Brazil ranked 13th (250 680 publications) among countries with the highest research productivity, corresponding to $11 \%$ and $16 \%$ of the first ranked countries, United States and China, respectively. ${ }^{1,2}$ In that period, the publications in Brazil increased by $30 \%$, twice the global mean, ${ }^{2}$ with over 50000 articles published in 2018 only.

A good example of that increase has been described in the study analyzing the number of papers published in Nature and Science from the University of São Paulo, University of Campinas, and the Federal University of Rio de Janeiro, from 1980 onwards. The publication counts were categorized by decade from 1980 to 2010 and for 2017. The authors have reported that those institutions together published 0.08 papers, on average, in each edition of those two journals. The total number of papers from those universities increased by $2200 \%$ from 1980 to 2017, with a higher representativity in the past decade (from 7 papers in 2010 to 23 in 2017). It is worth noting the increase in partnership with international institutions for the publication of scientific papers. ${ }^{3}$

It is important to emphasize that the reputation of teaching and research institutions is directly related to the volume, quality and global influence of their publications. It is worth noting that research depends on the availability of local resources and occasional opportunities for international collaboration. ${ }^{2}$

\section{Keywords}

Databases, Bibliographics; Scientific Publications; Brazil; Bibliometrics; Portals for Scientific Journals.
A supplement published by Nature in 2016 assessed a group of 68 journals, which represented less than $1 \%$ of the journals of the Journal Citation Reports but accounted for $30 \%$ of the citations in natural sciences from several countries. Count, fractional count, and weighted fractional count of articles were used for that assessment. The authors showed differences between countries of the same region, such as Chile and Brazil. ${ }^{4}$ The papers published by Chile showed a significant international participation via collaborative co-authorship and funding of high-cost projects, with an efficiency 15 times higher than that of Brazilian publications. In 2013, 717 Chilean articles were published, at the cost of 2 billion dollars, as compared to 670 Brazilian studies, at the cost of 30 billion dollars. ${ }^{4}$ However, the way the journals were selected as well as the metrics proposed in the supplement were harshly criticized. One of the reasons is the lack of representativeness, in that analysis, of the most influential journals of the 20th century, such as the New England Journal of Medicine, JAMA, BMJ, American Journal of Botany, Journal of Zoology, American Journal of Physical Anthropology, and Journal of Paleontology. The warning for the cost and efficiency of the publications with international collaboration was considerable. ${ }^{5}$

However, the percentage of Brazilian publications among the Top $1 \%$ of the most cited articles worldwide, those with a mean citation impact of 4.0 and over, more than doubled from 2011 to 2016, reaching the world mean between 2015 and 2016. When expanding that metric to the Top $10 \%$, only $6.4 \%$ of the Brazilian publications were contemplated, far below the world mean. ${ }^{1,2}$ Approximately one third of the Brazilian publications among the Top 10\% counted with the collaborative partnership of researchers who networked in 205 countries and obtained the highest number of citations, especially those in collaboration with emerging countries, such as China and India. ${ }^{2}$

Mailing Address: Marcelo Antônio Cartaxo Queiroga Lopes

Cardiocenter - Av. Ministro José Américo de Almeida, 1450, Torre, Hospital Alberto Urquiza Wanderley. Postal Code 58040-300, João Pessoa, PB - Brazil

E-mail: mqueiroga@cardiol.br, marcelocartaxoqueiroga@gmail.com 
It is important noting that the number of Brazilian periodicals comprising the database of international publications in the 2011-2016 period increased by $400 \%$, which might have influenced the difference in the metrics previously cited. ${ }^{5}$

Regarding the proportion of collaborations in Health Sciences and Biological Sciences, the United States was Brazil's main partner ( $40 \%$ to $50 \%)$, followed by European countries and Argentina. ${ }^{2}$ Papers published in partnership in Health Sciences have the highest citation impact, ranging from 4.13 (Spain) to 15.51 (Russia). ${ }^{2}$

The report by Clarivate Analytics has shown that the citations of Brazilian publications were below the world mean $(0.88 \%)$ in 2017 , despite the $15 \%$ increase in the number of citations in the past 20 years. The Brazilian fields with citation impact close to the world mean were environment, ecology, psychiatry, psychology, and mathematics. Regarding health sciences, the highest citation impact was observed in oncology, infectious diseases, neurology, odontology, surgery, oral medicine, and cardiovascular sciences, which were outshined only by internal medicine, whose citation impact was 0.87 , as compared to 0.76 of the other Brazilian publications. ${ }^{1,2}$

It is worth noting that the quality assessment of scientific productivity by using citation frequency has been harshly criticized. This metrics has limitations for the individual assessment of the researcher, the productivity of specific fields, and the comparability between journals of different coverages. This metrics is influenced by some factors, such as biases against the language of origin and the gender of authors, as well as the number of researchers involved in the scientific production. ${ }^{6}$

There is great discussion about the bias associated with the authorship proportion of men and women, either as first, last, or corresponding authors. A study carried out between 1980 and 2017 with data from 55085 articles from the Journal of the American College of Cardiology, Circulation, and European Heart Journal showed that female authors accounted for $33.1 \%$ of all authors but represented only $26.7 \%$ of first authors and $19.7 \%$ of senior authors. In addition, women corresponded to only $5 \%$ of the 100 most prolific authors in cardiovascular research in those journals. The authors concluded that the female representation in published cardiology research has increased over the past 4 decades, but women continue to be underrepresented when considering the total number of female researchers. ${ }^{7}$
The study analyzing citations from 2379 articles from the top 20 impact cardiology journals from the Entrez database on PubMed, in 2017, has reported that less than one third of the publications of single authors had a female authorship. Of the publications with multiple authors, only $15 \%$ of the corresponding authors were women. However, in articles with female researchers as senior authors, more women were coauthors as compared to those with male senior authors. That study has risen the hypothesis that senior authorship would be a way to identify cardiology research leadership, reinforcing the gender bias in cardiovascular science publications. ${ }^{8}$

It is worth highlighting the most studied and most cited fields in cardiovascular research. The study assessing the publications in 47 topics associated to the field of cardiovascular disease has listed 5 topic clusters with more than 400 publications each between 2014 and 2018. The cluster topic 'percutaneous coronary intervention and myocardial infarction' accounted for the greatest number of publications, followed by 'atrial fibrillation and catheter ablation', and 'cholesterol, lipids and atherosclerosis'. All those topics had weighted citation index for the field higher than 1, in addition to collaboration of foreign authors in one third of the articles. ${ }^{9}$

Regarding the impact of Brazilian papers in patent generation, 16 patents issued in the cardiovascular field have cited Brazilian papers on coronary artery bypass grafting, atherosclerotic plaque vulnerability and inflammation, statin therapy, and pulmonary hypertension. ${ }^{9}$ Most of those papers and patents cited originated from the São Paulo state, and the University of São Paulo accounted for $20 \%$ of the Brazilian production, followed by the University of Campinas and the Federal University of Rio de Janeiro. ${ }^{2,10}$

In Brazil, public universities were the leading institutions regarding research, citation impact, and relationship with industry. All 15 most prolific organizations, 13 universities and 2 specialized research institutes, are public. ${ }^{2}$

The increase in the Brazilian intellectual production has been attributed to the annual investment goal of $2 \%$ of the Gross Domestic Product (GDP) as part of the Brazilian Strategy in Science, Technology, and Innovation 20162019 (ENCTI 2016-19), which has focused on innovation to boost socioeconomic development. That annual investment goal, however, has not been met because the universities received only $60 \%$ of that value $(1.2 \%$ of the GDP) as a result of the world economic crisis. ${ }^{1,2}$ 
On March 29, 2019, the Brazilian government announced the preventive blockade of R $\$ 30$ billion (US\$ 7.5 billion) from the annual budget, including 2.2 billion from the budget of the Ministry of Science, Technology, and Innovations, which would be used to honor the ENCTI 2016-19. This hindered research financing in Brazil. Those sums were allocated as contingency funds and could only be spent in case of fiscal recovery or new income sources. ${ }^{11}$

With the Budget Law Project 2020, part of the resources destined to promote research, including those to provide for CAPES research grants, has been recovered. The mobilization of the scientific community was fundamental for scientific research and publications to gain additional momentum, ${ }^{12}$ although investments in research fell beneath the value suggested by the ENCTI 2016-19.

Additional initiatives, such as the maintenance of cardiovascular journals, promote the dissemination of Brazilian research. The Arquivos Brazileiros de Cardiologia ( ABC Cardiol) and the International Journal of Cardiovascular Sciences (IJCS), supported by the Brazilian Society of Cardiology, are examples of private funding for the dissemination of knowledge in the field.

The $A B C$ Cardiol is currently the cardiology publication with the highest impact in Brazil and Latin America. It is a 71-year-old journal, indexed in the major journal databases. The IJCS, created in 2015, replaced the Revista da SOCERJ and the Revista Brasileira de Cardiologia, created in 1998 and 2010, respectively. The IJCS was indexed in SciELO and DOAJ in 2017 and awaits assessment for indexation in Scopus and Web of Science. ${ }^{13,14}$

Approximately $65 \%$ of the original articles published in the $A B C$ Cardiol are contributions from postgraduation programs. Thus, the major cardiology publications are in accordance with the mission of the SBC, which aims at increasing and spreading knowledge about the cardiovascular science, representing cardiologists and promoting their development, in addition to enhancing cardiovascular health in Brazil. The creation of populationbased registries of cardiovascular disease is part of SBC attributions. ${ }^{15}$ Those population-based registries can contribute with information on several epidemiological aspects as well as with daily clinical practice, providing statistical data with potential impact on the improvement of routine medical practice. The use of population-based registries to assess the outcomes and cost-effectiveness of already implemented conducts has the advantage of analyzing interventions in the 'real world' in clinical practice. They have acquired substantial relevance in medical publications in recent decades and have been the object of research of the SBC in past years. ${ }^{16,17}$

Population-based registries and pragmatic clinical trials, designed to assess efficacy in real clinical practice, have less selection bias. ${ }^{16}$ The recent registry-based randomized controlled trials are defined as pragmatic clinical trials that use registries as a platform for data collection, randomization, and follow-up. ${ }^{18-20}$ Usually, the use of registries by the $\mathrm{SBC}$ has allowed the improvement of the knowledge about the Brazilian cardiovascular health and has provided actions to implement the best clinical practices. ${ }^{21-25}$ The SBC has taken initiatives regarding national research in partnership with international medical societies, such as the project "Best Practices in Cardiology - Brazil (BPC-Brazil)" with the American Heart Association (AHA). In the future, registries for quality control will be able to provide additional information to be conveyed into actions to improve cardiovascular care. ${ }^{17}$

Despite the substantial efforts of researchers and the highly qualified centers in research fields, the major obstacle to creating population-based registries in Brazil is that of a financial nature. The planning and execution of a research project require a model of promotion and achievement of resources. Gliklich et al. ${ }^{17}$ have suggested that, in case of registries of national or regional relevance, the costs can be subsidized by provider organizations (e.g., hospitals, clinics, government agencies, and foundations that support research), professional associations, medical specialty societies, and the pharmaceutical and medical device industries. The support of the private sector to fund cardiovascular health research in Brazil would be of great help. Although the SBC is not an institution primarily dedicated to research, it feels responsible, with the essential support of the public and private sectors, for proposing, promoting, exhorting, and disseminating effective actions to develop cardiovascular research in Brazil.

Aiming at valuing cardiovascular research, the SBC discloses the best studies performed in Brazilian postgraduation programs. The 'SBC Award for Best Theses - 2020 Edition' will be granted to the best dissertations and theses of postgraduation programs (professional and academic master's degree and doctorate degree) defended in 2019. The theses and dissertations will be selected from the Brazilian System of Postgraduation in Cardiology in Medicine I from CAPES programs. ${ }^{26}$

The recent challenge to human health represented by the COVID-19 pandemic, the increase in chronic diseases, and the population ageing will accelerate translational 
research, which will need to rapidly benefit patients via transfer of knowledge generated in laboratory benches.

In addition, the COVID-19 pandemic has emphasized the importance of collaboration of international research groups to solve an emerging global problem that causes many health losses and has severe socioeconomic implications.

Several molecular and genetic tools have been developed in recent years and will be able to accelerate the development of new drugs, such as vaccines. It is worth noting that the interdisciplinary activity will be strengthened, playing a fundamental role in the solution of common problems targeting a sustainable future for mankind.

The use of artificial intelligence, the incorporation of large databases with emphasis on big data, and the Precision Medicine will provide an immeasurable advance.

The integration of the world funding sources, with the participation of the private and public sectors, will allow the advance on understanding the pathophysiology of cardiovascular diseases and on multidisciplinary solutions for their treatment.

The population is increasingly aware of their food and their leisure activities. This is a unique opportunity for research focused on changes in lifestyle, such as the effects of food processing and practice of physical exercises on cardiovascular health.

In conclusion, despite the advance of medical research in Brazil in past decades, there are considerable gaps of knowledge to be filled regarding Brazilian cardiovascular health. The challenges in the coming years are significant, but the Brazilian cardiovascular research is being rapidly and proficiently organized, with a high potential of response to the Brazilian needs.

\section{Author contributions}

Conception and design of the research: Oliveira GMM, Lopes MACQ, Brasil D. Acquisition of data: Oliveira GMM, Lopes MACQ, Brasil D. Analysis and interpretation of the data: Oliveira GMM, Lopes MACQ, Brasil D. Writing of the manuscript: Oliveira GMM, Lopes MACQ, Brasil D. Critical revision of the manuscript for intellectual content: Oliveira GMM, Lopes MACQ, Brasil D.

\section{Potential Conflict of Interest}

No potential conflict of interest relevant to this article was reported.

\section{Sources of Funding}

There were no external funding sources for this study.

\section{Study Association}

This study is not associated with any thesis or dissertation work.

\section{References}

1. Cross D, Thomson S, Sinclair A. Research in Brazil: a report for CAPES by Clarivate Analytics [Internet]. 2017 [citado 30 maio 2020]. Disponível em: http://portal.andes.org.br/imprensa/noticias/imp-ult-992337666.pdf

2. A Pesquisa no Brasil: Promovendo a excelência. Análise preparada para a CAPES pelo Grupo Web of Science [Internet]. 2019 [citado 30 maio 2020]. Disponível em: https://propp.ufms.br/files/2019/09/Pesquisa-no-Brasil.pdf

3. Carli GJ, Pereira TC. Sharp rise in premier papers from Brazilian universities. Nature. 2018;556(7701):309.

4. NATURE INDEX. 2016 [Internet]. 2016 [citado 30 maio 2020]. Disponível em: https://www.natureindex.com/annual-tables/2016/institution/all/all

5. Silva V. Scientometrics: Nature Index and Brazilian science. An Acad Bras Ciênc. 2016;88(3):1597-9.

6. Opthof T. Differences in citation frequency of clinical and basic science papers in cardiovascular research. Med Biol Eng Comput. 2011;49(6):613-21.

7. Ouyang D, Sing D, Shah S, Hu J, Duvernoy C, Harrington RA, et al. Sex disparities in authorship order of cardiology scientific publications. Circ Cardiovasc Qual Outcomes. 2018;11(12):e005040.

8. Ouyang D, Harrington RA, Rodriguez F. Association between female corresponding authors and female co-authors in top contemporary cardiovascular medicine journals. Circulation. 2019;139(8):1127-9.

9. Krauskopf E. Cardiovascular disease: The Brazilian research contribution. Braz J Cardiovasc Surg. 2019;34(5):VI-IX.

10. Pontes P. Brazilian scientific production vs. innovation and technology. Braz J Otorhinolaryngol. 2015;81(4):343-4.

11. Escobar H. We can't take another hit like this': Brazilian scientists lament big budget freeze; 2019. Science [Internet]. [citado 30 maio 2020]. Disponível em: https://www.sciencemag.org/news/2019/04/we-cant-take-another-hitbrazilian-scientists-lament-big-budget-freeze

12. Mazza M. PLOA 2020 é aprovado pelo Congresso Nacional com pequenos acréscimos na Ciência; 2019. Jornal da Ciência [Internet]. [citado 30 maio 2020]. Disponível em: http://www.jornaldaciencia.org.br/ploa-2020-eaprovado-pelo-congresso-nacional-com-acrescimos-na-ciencia/

13. Evora PRB, Moreira LFP. The representativeness of the Arquivos Brasileiros de Cardiologia for Brazilian Cardiology Science. Arq Bras Cardiol. 2015;104(2):94-6.

14. Moreira LFP. Role of the International Journal of Cardiovascular Sciences in the Increase of Brazilian publications in Cardiology and Cardiovascular Sciences. Arq. Bras. Cardiol. 2016;107(1):1.

15. Rochitte CE, Quadros AS, Sousa AGMR, Ladeia AMT, Brandão AA, Lorenzo A, et al. Arquivos Brasileiros de Cardiologia (ABC Cardiol) and the new classification Qualis of Coordenação de Aperfeiçoamento de Pessoal de Nível Superior (CAPES). Arq Bras Cardiol. 2019;113(3):333-4. 
16. Barnish MS, Turner S. The value of pragmatic and observational studies in health care and public health. Pragmat Obs Res. 2017;8:49-55.

17. Agency for Healthcare Research and Quality [Internet]. Effective Health Care Program; 2020. [citado 30 maio 2020]. Disponível em: https:// effectivehealthcare.ahrq.gov/products/registries-guide-3rd-edition/research.

18. Gilmartin-Thomas JFM, Liew D, Hopper I. Observational studies and their utility for practice. Aust Prescr. 2018;41(3):82-5

19. Li G, Sajobi TT, Menon BK, Korngut L, Lowerison M, James M, et al. Registrybased randomized controlled trials- what are the advantages, challenges, and areas for future research? J Clin Epidemiol. 2016 Dec;80:16-24.

20. Bartlett VL, Dhruva SS, Shah ND, Ryan P, Ross JS. Feasibility of using real-world data to replicate clinical trial evidence. JAMA Netw Open. 2019;2(10):e1912869.

21. Wang R, Neuenschwander FC, Lima Filho A, Moreira CM, Santos ES, Reis $\mathrm{HJL}$, et al. Use of evidence-based interventions in acute coronary syndrome - Subanalysis of the ACCEPT registry. Arq Bras Cardiol. 2014;102(4):319-26.
22. Piva e Mattos LA, Berwanger O, Santos ES, Reis HJL, Romano ER, Petriz JLF, et al. Clinical outcomes at 30 days in the Brazilian Registry of Acute Coronary Syndromes (ACCEPT). Arq Bras Cardiol. 2013;100(1):6-13.

23. Berwanger O, Piva e Mattos LA, Martin JFV, Lopes RD, Figueiredo EL, Magnoni D, et al. Evidence-based therapy prescription in highcardiovascular risk patients: the REACT study. Arq Bras Cardiol. 2013;100(3):212-20.

24. Jardim PCBV, Souza WKSB, Lopes RD, Brandão AA, Malachias MVB, Gomes MM, et al. I RBH - First Brazilian Hypertension Registry. Arq Bras Cardiol. 2016;107(2):93-8

25. Albuquerque DC, Souza Neto JD, Bacal F, Rohde LEP, Bernardez-Pereira $\mathrm{S}$, Berwanger $\mathrm{O}$, et al. I Brazilian Registry of Heart Failure - Clinical Aspects, Care Quality and Hospitalization Outcomes. Arq Bras Cardiol. 2015;104(6):433-42.

26. Sociedade Brasileira de Cardiologia. Prêmio Tese da SBC. Edição 2020 [Internet]. 2020 [citado 30 maio 2020]. Disponível em: http://publicacoes. cardiol.br/portal/portal-publicacoes/portugues/premio-tese/Edital_ Premio_Teses_SBC.pdf 